\title{
Análise da Gestão de Resíduos Sólidos no Terminal Porto Novo do Porto do Rio Grande, Brasil *
}

\author{
Solid Waste Management Analysis in the Porto Novo Terminal of \\ Rio Grande's Port Facilities, Brazil
}

\author{
Alexandre Caldeirão Carvalho ${ }^{\circledR, 1} ;$ Patrizia Raggi Abdallah ${ }^{2}$
}

\section{RESUMO}

A partir de um estudo exploratório, descritivo e avaliativo, baseado em uma pesquisa de cunho qualitativo, foi efetuada a análise e avaliação da corrente gestão de resíduos sólidos do Terminal Porto Novo do Porto do Rio Grande. Primeiramente buscou-se avaliar a conformidade do instrumento de gestão utilizado, o Plano de Gerenciamento de Resíduos Sólidos (PGRS) do Porto do Rio Grande, com a legislação vigente que rege o tema, especificamente a Política Nacional de Resíduos Sólidos (PNRS) e a Resolução da Diretoria Colegiada (RDC) da Agência Nacional de Vigilância Sanitária (ANVISA) n 56/2008. Posteriormente, por meio de entrevistas e saídas de campo, a prática da gestão foi caracterizada e avaliada, desta forma foi possível efetuar a comparaçáo entre o instrumento de gestão utilizado pelo porto e suas práticas de gestão. Verificou-se que o instrumento de gestão está em conformidade com a norma legal e que é extremamente válido, porém, a prática de gestão constatada não se enquadra dentro daquilo que é determinado no PGRS. Cabe destacar que não é necessário uma alteração no planejamento da gestáo de resíduos, uma vez que este está plenamente de acordo com a legislação e atende às necessidades da área de abrangência, mas é essencial uma mudança na cultura portuária e na prática de gestão empregada, transformando a visão reativa e legalista em proativa e realista. Desta forma não apenas as demandas dos órgãos ambientais, como a confecção de um PGRS, serão atendidas, mas as necessidades reais do porto serão sanadas.

Palavras-chave: Zona Costeira, Gestão Ambiental Portuária, Sustentabilidade,

\section{ABSTRACT}

The economic and demographic growth, coupled with the technical development, brought civilization to a contemporary level of development never before dreamed. But this development exacerbated expressed that natural resources are not unlimited. In this context, fits the concept of sustainable development that can be seen as a new paradigm that seeks to guide the decision making in organizations and lists, search and consider topics such as economic development and improved quality of life of the human population, using appropriate natural resources and equitable international development. The present study found that the wealth produced by Brazil, for exports, and much of the imported inputs are released or received mostly (90\%) through the ports, constituting these as we logistical nodes, essential to national development. Thus, the present study, based on the integrated coastal management and building an exploratory, descriptive and evaluative, based on a qualitative research, carried out the analysis and assessed the current solid waste management of the Porto Novo Terminal of the Port of Rio Grande in

\footnotetext{
@ - corresponding author

1 - FURG - Universidade Federal do Rio Grande. Instituto de Oceanografia (IO) - Laboratório de Gerenciamento Costeiro (LABGERCO), Rio Grande, RS, Brasil.e-mail: acaldeirao@gmail.com

2 - FURG - Universidade Federal do Rio Grande, Instituto de Ciências Econômicas Administrativas e Contábeis (ICEAC), Rio Grande, RS, Brasil. e-mail: patrizia.abdallah@gmail.com
}

* Submission: May 8, 2012; Evaluation: June 12, 2012; Reception of revised manuscript: September 14, 2012; Accepted: September 17, 2012; Available on-line: September 19, 2012 
Brazil. First we sought to evaluate the compliance of the management tool used, the Solid Waste Management Plan (SWMP) of the Port of Rio Grande, with the current law governing the issue, specifically the National Policy on Solid Waste and the Resolution of the Board of Directors of the National Health Surveillance Agency No 56/2008. Later, through interviews and field trips, the practice of management was characterized and evaluated, in this way it was possible to make a comparison between the management tool used by the port and its management practices. It was found that management tool is in accordance with the legal standard, and that is extremely valid, however, the practical management detected does not fit within what is determined in the SWMP. It is worth mentioning that it is not necessary a change in the planning of waste management, since that is fully in line with law and meets the needs of the catchment area, but it is essential a change in the port culture and his practice of management, changing the 'end of pipe' management to a proactive management. Thus, not only the demands of environmental agencies, such as the making of a SWMP will be missed, but the real needs of the port will be resolved.

Keywords: Cost Zone, Port Environmental Management, Sustainability

\section{INTRODUÇÃO}

O notado crescimento econômico e demográfico, unido ao desenvolvimento técnico, trouxe a civilização contemporânea a um patamar de desenvolvimento nunca antes sonhado. Segundo Seiffert (2007: 15) esse desenvolvimento exacerbado colocou em evidência, no final do século XX, "que os recursos naturais e os serviços derivados deles não são ilimitados, e que sua escassez ou esgotamento constituem uma séria ameaça ao bem-estar presente e ao futuro da humanidade".

Assim, o conceito moderno de gestão ambiental não é um sinônimo de fiscalização ou reação, mas uma postura próativa, uma atitude que busca criar condiçóes para harmonizar o desenvolvimento humano com a necessidade de assegurar a perenidade dos recursos naturais.

Segundo Cicin-Sain (1998), o desenvolvimento sustentável pode ser visto como um novo paradigma, um novo modelo de ação, de tomada de decisão, que relaciona e busca equacionar temas como desenvolvimento econômico e aumento da qualidade de vida da população humana com o uso apropriado dos recursos naturais e o desenvolvimento equitativo internacional. De acordo com a autora, a partir do relacionamento dessas variáveis é possível manter o delicado equilíbrio entre desenvolvimento e preservação ambiental, por meio de um constante ajuste.

No intuito de manter esse ajuste afinado, a sociedade civil regula a atividade dos agentes econômicos, de tal forma que estes consigam desenvolver seus processos e atingir seus objetivos de forma ambientalmente sustentável. A própria legislação ambiental é fruto dessa demanda social. A Constituição Federal brasileira, Art. 225, afirma que "todos têm direito ao meio ambiente ecologicamente equilibrado, bem de uso comum do povo e essencial à sadia qualidade de vida, impondo-se ao Poder Público è coletividade o dever de defendêlo e preservá-lo para as presentes e futuras geraçōes".

Nesse sentido, segundo o Projeto Orla, a zona costeira aparece como uma área estratégica, a nível nacional e internacional, pois envolve "aspectos econômicos, ecológicos e socioculturais" (MMA, 2002: 11), de entre os quais cabe destacar a atividade portuária, pois o crescimento das correntes internacionais de comércio é sustentado fundamentalmente pelos portos, que dão suporte e favorecem o desenvolvimento industrial e comercial.

Inserida nesse contexto está a gestão ambiental portuária que, para Porto (2006), envolve duas facetas distintas e complementares, a da navegação e a das instalações portuárias propriamente ditas: "O impacto da embarcação no meio ambiente é mínimo se comparado ao das instalaçóes portuárias. (...) A poluição das embarcaçôes é originária dos acidentes com perda de carga. (...) contrariamente, as obras para implantação de instalaçôes portuárias, (...), impactam necessariamente o meio ambiente". Porto (2006: 168),

Segundo a ANTAQ (2011), dentro das atividades portuárias existem algumas que são potencialmente causadoras de impactos: (a) implantação de infraestrutura marítima ou terrestre; (b) os resíduos de embarcaçóes; (c) as operaçóes com embarcaçóes; (d) os serviços correlatos, como abastecimento de embarcaçóes e outros atendimentos; (e) as obras de acostagem; (f) os serviços de dragagem; (g) a geração de resíduos pela atividade portuária; (h) a operação de máquinas e veículos portuários; (i) o manuseio de cargas perigosas; (j) a limpeza de embarcaçóes; (k) a bioinvasão por meio da água de lastro e incrustaçóes nos cascos de embarcaçóes.

Dada a complexidade inerente a este processo de gestáo, torna-se relevante investigar aspectos específicos da corrente prática desenvolvida nos terminais portuários e sua aderência à legislação vigente. Assim, o presente trabalho se propóe analisar, dentro do marco da gestão ambiental portuária, a gestâo de resíduos sólidos nas instalaçóes públicas do Porto do Rio Grande.

Essa análise busca verificar, na área administrada diretamente pela Autoridade Portuária - Superintendência do Porto do Rio Grande (SUPRG), especificamente no terminal Porto Novo, a conformidade da corrente prática de gestão com o Plano de Gerenciamento de Resíduos Sólidos e com a legislação vigente, de forma específica a Política Nacional de Resíduos Sólidos (Lei 12.305 de 02 de agosto de 2010) e a Resolução da Diretoria Colegiada (RDC) da Agência Nacional de Vigilância Sanitária (ANVISA) nº 56 de 08 de agosto de 2008.

A metodologia pode ser caracterizada como de estudo exploratório, descritivo e avaliativo que, segundo Yin (2010: 24), "é usado, em muitas situaçôes, para contribuir ao nosso conhecimento dos fenômenos individuais, grupais, organizacionais, sociais, politicos e relacionados" e compreender fenômenos tidos como complexos.

Para tanto, foi efetuada uma revisão bibliográfica que buscou embasar a necessidade de uma gestão integrada de resíduos sólidos, analisando o aparente conflito entre o paradigma empresarial e o desenvolvimento sustentável, e relacionando esse aparente conflito à gestáo empresarial e à 
legislação vigente. Também foi analisado o Plano de Gestão de Resíduos Sólidos (PGRS) do Porto do Rio Grande e em sucessivas visitas ao porto foi verificada sua aplicação prática. Além disso, foram entrevistados tanto os operadores portuários que atuam na área de abrangência do Terminal Porto Novo, como a responsável pela Divisão de Meio Ambiente Saúde e Segurança do Porto do Rio Grande.

\section{A PROBLEMÁTICA NACIONAL DOS RESÍDUOS SÓLIDOS}

Atualmente, segundo Miller (2007: 33), vive-se um paradigma produtivo insustentável, onde a maioria das naçóes produz grandes quantidades de produtos e serviços para atender as necessidades de suas populaçóes e ao mesmo tempo dispersa "grandes quantidades de resíduos, poluição e calor de baixa qualidade no ambiente". Partindo do pressuposto que o ambiente possui uma capacidade de produção de recursos limitada ou finita, este paradigma produtivo ocasionará o esgotamento de recursos e a destruição do sistema de produção dos mesmos. Como já foi enunciado, é essencial uma mudança de paradigma, pois a economia atualmente instaurada em boa parte dos países, segundo Miller (2007), é de alta produtividade, devendo ser mudada para economias de reciclagem, de reaproveitamento e de baixa produtividade ou sustentáveis.

Segundo Valle (2006: 9), nosso modelo urbanísticoindustrial traz "como contrapartida, a poluição ambiental das águas, do solo e do ar. A concentração de milhóes de pessoas nos centros urbanos tem deixado grande parte da população sem nenhuma perspectiva de atendimento às suas necessidades mais elementares, como alimentação, moradia, abastecimento de água, tratamento sanitário, serviços de coleta, destinação de lixo urbano e drenagem fluvial, elementos essenciais para a saúde da população".

A gestão integrada de resíduos sólidos busca "conceber, implementar e administrar sistemas de manejo de residuos sólidos urbanos, considerando uma ampla participação dos setores da sociedade e tendo como perspectiva o desenvolvimento sustentável' (Comissão Mundial Sobre Meio Ambiente e Desenvolvimento, 1991: 46). A nível nacional, a responsabilidade por gerir os resíduos sólidos e perigosos está definida na Constituição Federal, art. 23, incisos VI e IX e art. 30, incisos I e V. O art. 23 define que a melhoria do saneamento básico é de competência comum da União, dos Estados e do Distrito Federal e dos Municípios e o art. 30 define que legislar sobre assuntos de interesse local, entre eles a limpeza urbana, é competência dos municípios. Nesse contexto, o município é o principal ator envolvido, pois é ele o responsável direto pelos resíduos gerados em seu território, "com exceção dos de natureza industrial, mas incluindo-se os provenientes dos serviços de saúde" (Zveibil, 2001: 2).

Segundo Mesquita (2007: 11), "(...) a situação do manejo de resíduos sólidos no país é preocupante, principalmente no que diz respeito à questão da disposiçấo final, uma vez que 63,3\% dos municípios brasileiros utilizam lixóes como forma de disposição dos resíduos sólidos urbanos, $18,4 \%$ utiliza aterros controlados e 13,8\% dispóe os resíduos em aterros sanitários".

Dentre os serviços elencados no rol do saneamento básico, a coleta de resíduos sólidos urbanos obedece a uma pressão exercida pela população, pois a gestão dos resíduos sólidos urbanos, além de essencial, é a parte mais visível dos sistemas de saneamento básico. Segundo IPT, 1995 apud Carvalho (2001), os "serviços de limpeza urbana absorvem entre 7\% e $15 \%$ dos recursos de um orçamento municipal, dos quais cerca de $50 \%$ são destinados à coleta e ao transporte de lixo".

Para uma gestão integrada de resíduos sólidos é necessária a articulação entre "as açôes normativas, operacionais, financeiras e de planejamento" (Zveibil, 2001: 8), pois estão todas profundamente interligadas e são todas mutuamente dependentes. Os Municípios, últimos responsáveis pelo gerenciamento dos resíduos, tratam-nos simplesmente como algo não desejado, a ser recolhido, transportado e que pode ou não receber um tratamento mecânico ou manual para finalmente ser deposto em aterros.

De acordo com a Agenda 21, capítulo 21, "o manejo ambientalmente saudável de resíduos deve ir além da simples deposiçâa ou aproveitamento por métodos seguros dos residuos gerados e buscar desenvolver a causa fundamental do problema, procurando mudar os padröes não-sustentáveis de produção e consumo. Isto implica na utilização do conceito de manejo integrado do ciclo vital, o qual apresenta oportunidade única de conciliar o desenvolvimento com a proteção do meio ambiente." (Zveibil, 2001: 8)

A Lei 12.305/2010 (Política Nacional de Resíduos Sólidos - PNRS, em seu art. $3^{\circ}$ ) define destinação final ambientalmente adequada, como a destinação de resíduos que inclui reutilização, reciclagem, compostagem, recuperação e aproveitamento energético, ou outras destinaçóes admitidas pelos órgãos competentes do Sistema Nacional do Meio Ambiente (SISNAMA), do Sistema Nacional de Vigilância Sanitária (SNVS) e do Sistema Único de Atenção à Sanidade Agropecuária (SUASA). Assim, a disposiçãoo final deve observar normas operacionais específicas de modo a evitar danos ou riscos à saúde pública e à segurança e a minimizar os impactos ambientais adversos.

A gestão de resíduos sólidos é complexa. O processo, que envolve descarte, coleta e processamento, é desenvolvido por meio de diversos atores, de modo que o tratamento meramente técnico dessas questóes tem apresentado resultados pouco animadores. Além disso, há problemas com a disponibilização de recursos financeiros, pois o descarte de materiais é cada vez maior por causa do aumento da aglomeração urbana, sendo necessários grandes investimentos para a aquisição de equipamentos, treinamento, capacitação, controle e custeio de todo o sistema de manejo dos resíduos sólidos.

"De natureza complexa, o problema deixa de ser simplesmente uma questão de gerenciamento técnico para inserir-se em um processo orgânico de gestão participativa, dentro do conceito de gestão integrada de resíduos sólidos. A gestão que se propóe envolve a articulação com os diversos niveis de poder existentes e com os representantes da sociedade civil nas negociaçóes para a formulação e implementação de politicas públicas, programas e projetos" Mesquita (2007: 11-12).

Desta forma, a gestấo de resíduos sólidos coloca-se como uma das questóes centrais do desenvolvimento sustentável. O tratamento dos resíduos, além de beneficiar populaçóes e organizaçôes, pode ser uma fonte de matéria-prima para vários processos produtivos, criando um ciclo virtuoso, pois, além de tratar os resíduos, pessoas e organizaçóes 
podem obter benefícios econômicos, utilizando os materiais reciclados ou vendendo-os e gerando receitas e reduzindo os impactos ambientais dos processos produtivos.

Em seu artigo $6^{\circ}$, a Lei $12.305 / 2010$ elenca os princípios da PNRS: prevenção e precaução, o poluidor-pagador e o protetor-recebedor, a visão sistêmica (sócio - econômico cultural), o desenvolvimento sustentável, a ecoeficiência, o reconhecimento do resíduo sólido como bem econômico, passível de reutilizaçáo, o respeito às idiossincrasias locais, o direito da sociedade à informaçáo e ao controle e a proporcionalidade de razoabilidade. Pode-se ressaltar que a efetividade das açóes descritas e propostas na PNRS não são de responsabilidade apenas do poder público, mas o envolvimento do setor empresarial e da coletividade são essenciais. (Lei 12.305/10, Art. 21)

A PNRS não é um instrumento isolado, mas busca apoiarse em alguns instrumentos próprios da Política Nacional do Meio Ambiente (Lei 6.938/81), a saber, (a) os padróes de qualidade ambiental, (b) o Cadastro Técnico Federal de Atividades Potencialmente Poluidoras ou Utilizadoras de Recursos Ambientais, (c) o Cadastro Técnico Federal de Atividades e Instrumentos de Defesa Ambiental, (d) a avaliação de impactos ambientais, (e) o licenciamento e a revisão de atividades efetiva ou potencialmente poluidoras, (f) os termos de compromisso e os termos de ajustamento de conduta, bem como o incentivo à adoçáo de formas de cooperação com vistas ao aproveitamento das sinergias do sistema.

Nesse sentido, em seu artigo $9^{\circ}$, a PNRS enumera hierarquicamente as açóes que deveriam ser adotadas por um sistema integrado de gerenciamento de resíduos sólidos, a saber: (a) não geração de resíduos, (b) redução na geração de resíduos, (c) reutilização dos resíduos gerados, (d) reciclagem de resíduos, (e) tratamento de resíduos sólidos, (f) disposição final ambientalmente adequada dos rejeitos.

A gestão integrada dos resíduos sólidos gerados nos respectivos territórios cabe aos municípios, sem excluir de sua responsabilidade, o gerador pelo gerenciamento de seus resíduos, e igualmente sem prejuízo das competências de controle e fiscalização dos órgãos federais e estaduais do SISNAMA, do SNVS e do SUASA.

Como já foi explicitado anteriormente o processo de gestáo dos resíduos sólidos é complexo, envolve recursos, tempo, área física e a colaboração de toda a sociedade. A interação dos atores públicos com as organizaçôes privadas é essencial para que os resíduos gerados ao longo do processo produtivo sejam destinados de forma ambientalmente adequada.

Ao pensar-se o processo produtivo, principalmente de um país como o Brasil que possui grande interesse no comércio internacional, deve-se ter em conta os nós logísticos, os locais para os quais confluem os produtos que serão destinados ao mercado externo. Esses locais, devido à diversidade de usos e à concentração de mercadorias, merecem atenção especial. Sendo assim, os portos, localizados em áreas de extrema vulnerabilidade ambiental, devem ser alvo de uma atenção especial por parte do poder público e da sociedade civil.

\section{AMBIENTE PORTUÁRIO E SUA IMPORTÂNCIA PARA O DESENVOLVIMENTO BRASILEIRO}

Desde a antiguidade o mar foi o caminho do desenvolvimento. Das navegaçôes bárbaras e romanas, passando pelas grandes navegaçóes ibéricas e saxônicas, aos nossos dias, não há dúvidas que o desenvolvimento econômico passa pelas rotas marítimas. Segundo o sítio eletrônico ports.com, o mundo conta com 8.293 estruturas portuárias espalhadas em 222 países, incluindo 13 instalações localizadas na Antártica.

Ainda segundo o referido sítio eletrônico, o Sistema Portuário Internacional está espalhado pelos cinco continentes, sendo a Europa (3.024) e a América do Norte (apenas Estados Unidos e Canadá - 2.293) aqueles que contam com o maior número de portos. A América do Sul conta apenas com 453 portos, 88 dos quais estáo no Brasil.

Segundo dados da Balança Comercial Brasileira, "em 2011, o comércio exterior brasileiro registrou corrente de comércio recorde de US\$ 482,3 bilhöes, com ampliação de 25,7\% sobre 2010, quando atingiu US\$ 383,7 bilhöes. As exportações encerraram o periodo com valor de US\$256,0 bilhóes e as importaçôes de US\$226,2 bilhöes, resultados igualmente recordes. Em relação a 2010, as exportaçôes apresentaram crescimento de $26,8 \%$ e as importaçóes de $24,5 \%$. (...) O saldo comercial atingiu US\$29,8 bilhóes em 2011, significando ampliação de 47,9\% sobre o consignado no ano anterior, de US\$ 20,1 bilhóes, motivado por um maior aumento das exportaçóes em relação às importaçôes. Do lado da importação, as compras de matérias-primas e intermediários representaram 45,1\% da pauta total, e as de bens de capital, 21,2\%, demonstrando que a pauta brasileira de importação é fortemente vinculada a bens direcionados à atividade produtiva. As importaçôes de bens de consumo representaram $17,7 \%$ e as de combustiveis e lubrificantes, 16,0\%. Sobre 2010, a categoria de combustiveis e lubrificantes foi a que registrou maior crescimento, de 42,8\%, seguida de bens de consumo $(+27,5 \%)$, matérias-primas e intermediários $(+21,6 \%)$ e bens de capital $(+16,8 \%)$ ". MDIC (2012)

Para esse patamar comercial é essencial uma rede logística integrada, que possua pontos estratégicos de entronizaçáo e exteriorização de mercadorias. Portanto, é uma questão estratégica o aproveitamento da zona costeira para o estabelecimento de nós logísticos, os portos.

A Lei 9.966 , de 28 de abril de 2000, que "dispóe sobre a prevenção, o controle e a fiscalização da poluiçáo causada por lançamento de óleo e outras substâncias nocivas ou perigosas em águas sob jurisdição nacional e dá outras providências", caracteriza, em seu art. $2^{\circ}$ (subitem XII), um porto organizado como aquele "construído e aparelhado para atender às necessidades da navegação e da movimentação e armazenagem de mercadorias, concedido ou explorado pela União, cujo tráfego e operaçôes portuárias estejam sob a jurisdição de uma autoridade portuária"; e, instalação portuária ou terminal como aquela "explorada por pessoa jurídica de direito público ou privado, dentro ou fora da área do porto organizado, utilizada na movimentação e armazenagem de mercadorias destinadas ou provenientes de transporte aquaviário".

O complexo cenário portuário brasileiro é composto, atualmente, por duas instituiçóes a nível nacional que exercem 
autoridade sobre os portos: a Secretaria Especial de Portos da Presidência de República (SEP/PR) e a Agência Nacional de Transportes Aquaviários (ANTAQ). Além destas instituições existem as autoridades portuárias, as administradoras diretas dos portos. As Autoridades Portuárias, 24 ao todo, segundo a Lei 9.966/00 são responsáveis "pela administração do porto organizado, competindo-lhe fiscalizar as operaçôes portuárias $e$ zelar para que os serviços se realizem com regularidade, eficiência, segurança e respeito ao meio ambiente".

Os portos brasileiros atendem aos mais diversos usos e, segundo a ANTAQ, movimentaram mais de 290 milhóes de toneladas de carga nas áreas geridas diretamente pela administração pública, ou seja, sem contar os Terminais de Uso Privativo (TUP).

Para movimentar esse volume de carga é necessário possuir, não apenas um grande número de terminais, mas grandes estruturas portuárias, capazes de concentrar grandes quantidades de carga, criando sinergias na logística nacional e reduzindo custos para os importadores e exportadores.

\section{ANÁLISE DO PLANO DE GERENCIAMENTO DE RESÍDUOS SÓLIDOS DO PORTO DE RIO GRANDE}

Inicialmente o PGRS do Porto do Rio Grande será descrito, sendo seus principais aspectos detalhados e posteriormente será efetuada uma análise de aderência do Plano à RDC nº 56.

\subsection{Caracterizaçáo da área de estudo}

O Porto Novo, terminal de uso público, administrado diretamente pela Superintendência do Porto do Rio Grande (SUPRG), é um terminal que congrega vários operadores portuários, alguns ocupando áreas físicas no terminal e outros apenas efetuando carga e descarga de mercadorias e operação de navios.

Atualmente, segundo o Plano de Zoneamento das Áreas do Porto Organizado do Rio Grande, o Porto Novo possui sete áreas especializadas, a saber: (1) área de turismo, lazer e preservação ambiental, (2) área militar, (3) área de carga geral, (4) área "roll-on/roll-off", (5) área de contêineres e fertilizantes, (6) área de construção e reparo naval e (7) área de expansão.

$\mathrm{Na}$ prática, conforme um levantamento de campo efetuado nas dependências do Porto Novo, a área 5, destinada às operações com contêineres e fertilizantes foi em parte destinada a operaçóes de construção e reparo naval. Essa diminuição na área operacional do Porto trás atrelada a si um aumento da complexidade das operaçóes, pois estas não diminuíram, mas se concentraram em uma área menor.

Ao longo do levantamento de campo foram encontradas áreas cedidas a atividades que nada têm a ver com a dinâmica operacional portuária, por exemplo, parte de um dos armazéns do Porto foi remodelada e abriga uma quadra esportiva dedicada ao futsal.

A área externa do terminal abriga uma grande gama de equipamentos, utilizados em sua maioria para a operação de carga e descarga de navios. Essas áreas podem ser consideradas como áreas multiuso ou multi-propósito, pois operaçóes diversas ocorrem de forma concomitante sob responsabilidade de vários atores. Não foi constatado, nos diversos contatos com pessoas ligadas à SUPRG que se tenha uma noção exata das operaçóes desenvolvidas por cada um dos atores que desenvolvem suas atividades na área.

As estruturas de armazenagem presentes também podem ser consideradas multi-propósito, uma vez que foram constatados diversos usos: os armazéns abrigam desde áreas administrativas, de convivência e refeitórios, até garagens, almoxarifados e armazenagem de carga propriamente dita.

Ao longo das diversas visitas efetuadas às instalaçóes do terminal foram identificados os seguintes atores que possuem contratos de arrendamento de áreas e de movimentaçáo de mercadorias com a SUPRG: (a) Cisa Trading, (b) Sagres Agenciamentos Marítimos Ltda., (c) Serra Morena Corretora Ltda., (d) Sampayo Nickhorn S.A., (e) Supermar S.A., Agência Marítima Orion Ltda., (f) Vanzim Serviços Aduaneiros Ltda., (g) General Motors, (h) Guanabara Veículos e (i) Ecosorb.

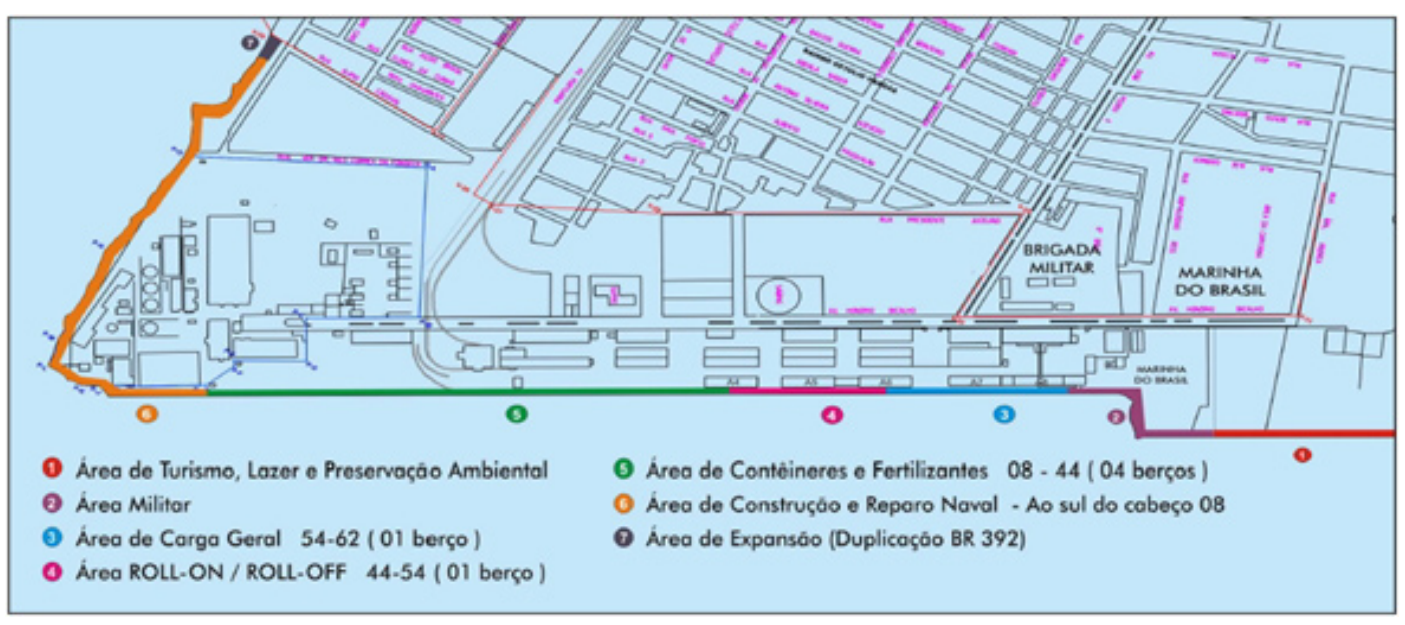

Figura 1. Esquema da área do Porto Novo.

Figure 1. Porto Novo - Terminal's layout.

Fonte: Plano de Zoneamento das Áreas do Porto Organizado do Rio Grande, v.2, 2010, p. 7 


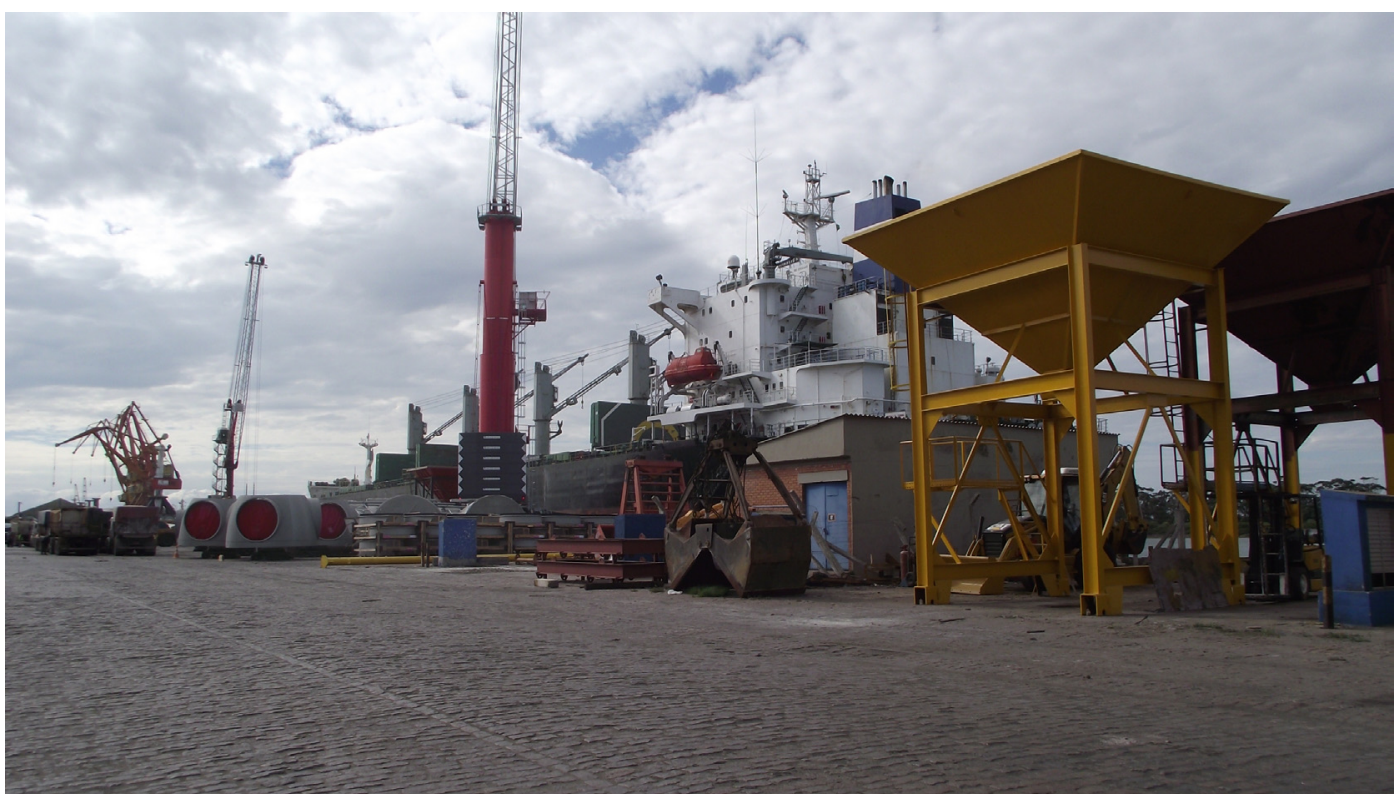

Figura 2. Área de Operaçóes do Porto Novo.

Figure 2. Operations Area of Porto Novo Terminal.

Fonte: $\mathrm{O}$ autor

As áreas ocupadas pelos diversos atores são muito dispares. Enquanto alguns, como a General Motors, possuem áreas cercadas para uso exclusivo, outros operam com bases "móveis", contêineres adaptados que servem como área administrativa e base operacional.

Segundo entrevista efetuada com o gerente da Sampayo Nickhorn, as áreas ocupadas pelos diversos atores não são fixas, pois os contratos firmados com a Autoridade Portuária, com duraçáo de um ano, referem-se à movimentaçáo de carga e a área cedida, teoricamente, pode variar a cada novo contrato assinado.

Portanto, a complexidade das operaçóes se multiplica, pois, na maioria dos casos, não há uma apropriação do espaço por parte dos operadores, sendo este identificado, a grosso modo, como "área pública". Claro está que os operadores portuários providenciam os reparos mínimos às estruturas e alguns, como a Sagres Agenciamento Marítimo, possuem colaboradores dedicados ao constante reparo e adaptação das estruturas, principalmente buscando evitar a entrada de fauna sinantrópica nociva, especificamente pombos, no interior dos armazéns.

\subsection{Descriçáo do Plano de Gerenciamento de Resíduos Sólidos do Porto de Rio Grande}

O Plano de Gerenciamento de Resíduos Sólidos (PGRS) é o documento que plasma as ações de gestão de resíduos sólidos em uma organização. Assim, a corrente análise utilizará os dados do PGRS do Porto do Rio Grande, conforme SUPRG (2010) para descrever a sistemática de gestão de resíduos proposta pela Autoridade Portuária.

A área de abrangência do Plano compreende o Terminal Porto Velho e o Terminal Porto Novo. As demais áreas do Porto Organizado, denominadas no PGRS como Zonas Indiretas, estão sob administração de concessionárias.
Cabe ressaltar que a presente análise focou as operaçóes desenvolvidas na área conhecida como Porto Novo.

A RDC n ${ }^{\circ} 56$ exige que as Autorizaçóes de Funcionamento de Empresas (AFE), das empresas terceirizadas que trabalham com resíduos sólidos dentro da área de escopo do Plano constem do mesmo. Estas autorizaçóes encontram-se no Anexo B do PGRS/SUPRG.

Após relacionar a legislação aplicada, o Plano passa a diagnosticar a situaçáo atual, os geradores, a tipologia de resíduos gerados e descreve os fatores de risco ambiental na circunvizinhança do Porto. O levantamento é quantitativo, e sua classificação é de acordo com a legislação sanitária e ambiental.

Os dados estão desatualizados e seria mais interessante ao plano que constassem de um anexo, pois este poderia ser facilmente atualizado, enquanto que nos moldes atuais, para efetuar a atualização dos dados, é necessário lançar uma atualização de todo o PGRS/SUPRG.

O Plano faz uma descrição dos procedimentos atuais de gerenciamento de resíduos sólidos. Essa gestáo busca, a partir da implantação dos procedimentos de segregação, acondicionamento, coleta, armazenagem, transporte, tratamento e destinação final, "(a) evitar acidentes, (b) evitar a proliferação de vetores, (c) minimizar o impacto visual e olfativo, (d) reduzir a heterogeneidade dos resíduos e (e) facilitar a realização da etapa de coleta." (SUPRG, 2010: 39)

Segundo o PGRS/SUPRG, a destinação final dos resíduos comuns não-recicláveis da área de administração direta da Superintendência do Porto do Rio Grande é o Aterro Sanitário do Município do Rio Grande. (SUPRG, 2010: 36)

As diferentes categorias de resíduos gerados na estrutura sob responsabilidade direta da SUPRG, tipificadas segundo os grupos estabelecidos pela RDC n ${ }^{\circ} 56$ são: Grupo A - 
Lixo Ambulatorial e Lixo Naval, Grupo B - Medicamentos Vencidos, Resíduos de Pintura, Materiais Contaminados com Produtos derivados de Petróleo, Lâmpadas, Pilhas e Baterias, Cartuchos de Impressora, Resíduos de Varredura, Resíduos Oriundos de Cargas Perigosas, Grupo D - Lixo Limpo.

Os métodos de transporte, tratamento e disposição final dos resíduos gerados nas instalaçóes do Porto encontramse detalhados ao longo do PGRS/SUPRG e se adéquam às exigências da RDC $\mathrm{n}^{\circ} 56$. Igualmente, os procedimentos para tratamento e disposição final dos resíduos gerados à bordo de embarcaçôes encontra-se descrito.

O Plano elenca como instrumentos de gestáo de resíduos sólidos "medidas de redução de geração de resíduos, programas sociais, educativos, culturais e de mobilização social" (SUPRG, 2010: 59). Além disso, as açóes do PGRS/SUPRG estão integradas com os programas de coleta seletiva implantados no Município do Rio Grande.

$\mathrm{O}$ registro das informaçóes referentes ao sistema de gestão do PGRS/SUPRG é organizado em planilhas. O registro dessas informaçóes é efetuado pela empresa terceirizada que se encarrega da coleta de resíduos nas áreas de abrangência do Plano. Conforme descrito no PGRS/SUPRG, são tomadas açóes pontuais "em razão do tipo de carga a ser movimentada" (SUPRG, 2010: 60)

O PGRS/SUPRG leva em conta ainda uma análise e uma avaliação periódica dos tipos de resíduos e efluentes gerados, de acordo com seu risco. "Os instrumentos usados para diagnosticar e prognosticar situaçóes relativas ao gerenciamento dos resíduos sólidos são relatórios específicos dos serviços de carga e descarga de navios, relatório mensal contendo planilha detalhada de quantitativos e qualitativos dos resíduos sólidos." (SUPRG, 2010: 62)

No item 6 do PGRS/SUPRG são definidas as responsabilidades do gestor, dos setores envolvidos e do responsável técnico, dos concessionários e dos terceiros contratados, encerrando assim o Plano no item 7, com os cronogramas de implantação e avaliação.

Cabe destacar a abrangência do PGRS/SUPRG, que em pouco mais de 65 páginas descreve, de forma clara e estruturada, a gestáo de resíduos nas instalaçóes administradas diretamente pela Superintendência do Porto do Rio Grande.

Além disso, todas as exigências levantadas pela RDC ${ }^{\circ}$ 56/2008 estáo sendo atendidas pelo PGRS/SUPRG, mesmo que o plano ainda apresente a estrutura da antiga RDC $\mathrm{n}^{\circ}$ 342/2002 "Termo de Referência para Elaboração do Plano de Gerenciamento de Residuos Sólidos - PGRS, para Instalaçóes Portuárias, Aeroportuárias e Terminais Alfandegados de Uso Público". É importante ressaltar que o PGRS/SUPRG foi aprovado pela ANVISA em 2007 e a atual revisão lhe confere o caráter de um instrumento de gestão integrada.

\subsection{Análise documental da aderência do PGRS do Porto do Rio Grande à RDC n ${ }^{\circ} 56$ da ANVISA}

O Plano de Gerenciamento de Resíduos Sólidos do Porto Novo (PGRS/SUPRG) possui identificados tanto seu representante legal como o responsável técnico. Da mesma forma a tipologia dos resíduos gerados é elencada.
O plano determina que os locais de geração dos resíduos encontrem-se identificados, bem como o gerador e as quantidades de resíduos gerados em cada, uma vez que há áreas do terminal arrendadas a outras empresas. Segundo o plano, a segregação dos materiais deve ser feita no momento do descarte como forma de prevenir a contaminação cruzada. Para tal, foram disponibilizados contentores especiais, com tampa e identificados pelo sistema de cores da resolução do Conselho Nacional do Meio Ambiente, CONAMA n ${ }^{\circ} 275$, estabelecendo o código de cores para os diversos tipos de resíduos, que deve ser aplicado aos coletores, aos recipientes de transporte e aos veículos transportadores de resíduos.

Os procedimentos utilizados pela Superintendência do Porto de Rio Grande (SUPRG) encontram-se detalhados no plano. Segundo o mesmo, os sacos que contêm os resíduos encontram-se identificados e os recipientes para deposiçáo dos resíduos são impermeáveis, de material lavável, e dotados de tampas íntegras, mas não consta do PGRS/SUPRG o procedimento de lavagem e desinfecção dos contentores de resíduos.

O plano determina que os resíduos coletados a bordo das embarcaçôes atracadas sejam autoclavados e suas cinzas dispostas em vala séptica.

De forma geral o PGRS/SUPRG se adéqua à legislação e às normas, sua versão é de 2010, porém o mesmo encontra-se em processo de revisão para que possa adequar-se totalmente à $\mathrm{RDC} \mathrm{n}^{\circ} 56$.

A partir da análise de documentos é possível afirmar que o Plano de Gerenciamento de Resíduos Sólidos do Porto Novo atende, documentalmente, à RDC nº 56.

\subsection{Análise da Corrente Gestáo de Resíduos Sólidos no Terminal Porto Novo do Porto do Rio Grande}

Em uma avaliação inicial da corrente gestão de resíduos do Terminal Porto Novo é possível identificar várias não conformidades, desde a precária caracterização da área, feita por meio de instrumentos como o Plano de Zoneamento das Áreas do Porto Organizado do Rio Grande, que está desatualizado e náo atende às necessidades de gestấo, uma vez que não é suficientemente detalhado e não exprime a realidade das operaçóes desenvolvidas, até a ausência de uma base de dados confiável de contatos dos diversos atores que possuem atividades ou interesses na zona em questáo.

Inicialmente um Plano de Gerenciamento de Resíduos Sólidos precisa caracterizar e servir de instrumento de análise da realidade portuária, de tal forma que a compreensão das operaçôes desenvolvidas e as relaçôes que se tecem no âmbito portuário sejam compreendidas, assimiladas e geridas.

Atualmente, a Divisão de Meio Ambiente, Saúde e Segurança (DMASS) da Superintendência do Porto do Rio Grande (SUPRG) não possui informaçóes sistematizadas a respeito da ocupação da área do Porto Novo, nem mesmo da carga presente nos armazéns. Assim, sem conhecer de forma sistemática as atividades dos diferentes operadores portuários é muito difícil prever a quantidade e tipologia de resíduos gerados, organizar sua retirada e efetuar as atividades de acompanhamento e fiscalização próprias da Autoridade Portuária. 
Em entrevista com a responsável pela área de ambiente da SUPRG, foi relatado que a maioria dos operadores portuários não possui um PGRS documentado, mas que a retirada de resíduos é feita por empresas terceirizadas contratadas pelos empreendedores e que muitas vezes a própria SUPRG retira os resíduos nos coletores dispostos na área operacional do Porto.

Já entre os operadores portuários, alguns afirmam que entregaram os documentos, e alguns inclusive mostraram os protocolos de entrega emitidos pela DMASS, outros desconhecem a existência do PGRS ou sua função dentro da dinâmica operacional portuária.

Tal constataçáo demonstra, inicialmente, que existe um problema de comunicação entre os operadores portuários e a Divisão de Meio Ambiente do porto. Demonstra também que há problemas na custódia dos documentos entregues à Divisão. Cabe destacar ainda que tais problemas se devem ao caráter político dado à Divisão, uma vez que o responsável pela gestão ambiental do porto é escolhido politicamente e não é um funcionário de carreira. Assim, a cada mudança de governo, e no Rio Grande do Sul houve três governadores de três partidos diferentes nos últimos três mandatos, há um novo responsável pela Divisão de Meio Ambiente, o que unido a um sistema de gestáo deficitário, resulta na perda da memória organizacional.

Um processo de sucessão correto, unido a uma sistemática administrativa correta deveria preservar os dados e demais práticas correntes, de tal forma que a cada nova gestão, o processo se aprimorasse e não houvesse a necessidade de iniciar as atividades praticamente do zero.
O Porto Novo possui 14 pontos de coleta de resíduos sólidos, 11 deles equipados com tambores coletores de 320 litros, alguns identificados e outros sem aparente identificação. No total o terminal conta com 22 tambores coletores. Nas duas zonas restantes são utilizados coletores plásticos coloridos, porém, uma dessas zonas está indisponível para a maioria dos usuários, por encontrar-se atrás de uma cerca, na área administrada pela empresa Cisa Trading. O décimo quarto ponto de coleta é coberto por um contêiner metálico utilizado para a coleta de resíduos oriundos da construção civil, este obviamente é um ponto móvel, devendo atender necessidades pontuais.

Em diversas áreas do porto foram verificadas situaçóes de deposição de materiais a céu aberto, por exemplo, paletes usados e material de construção. Esse tipo de material, além de causar problemas estéticos, dando a impressão de que existe desleixo, proporciona abrigo a vários elementos da fauna sinantrópica nociva. Essa fauna também se beneficia dos resíduos de alimentos deixados para trás após a operação portuária, do acúmulo de água a causa das imperfeiçôes do piso e das aberturas existentes nos armazéns, que são um local perfeito de abrigo.

A atual gestão de resíduos do Porto Novo precisa ser revista. Alguns pontos básicos ligados aos processos de gestão devem ser atendidos. Ninguém administra o que não conhece, portanto, é essencial que a atual administração conheça os atores presentes na área portuária, saiba qual sua capacidade de movimentação, verifique as operaçóes e busque formar alianças estratégicas.

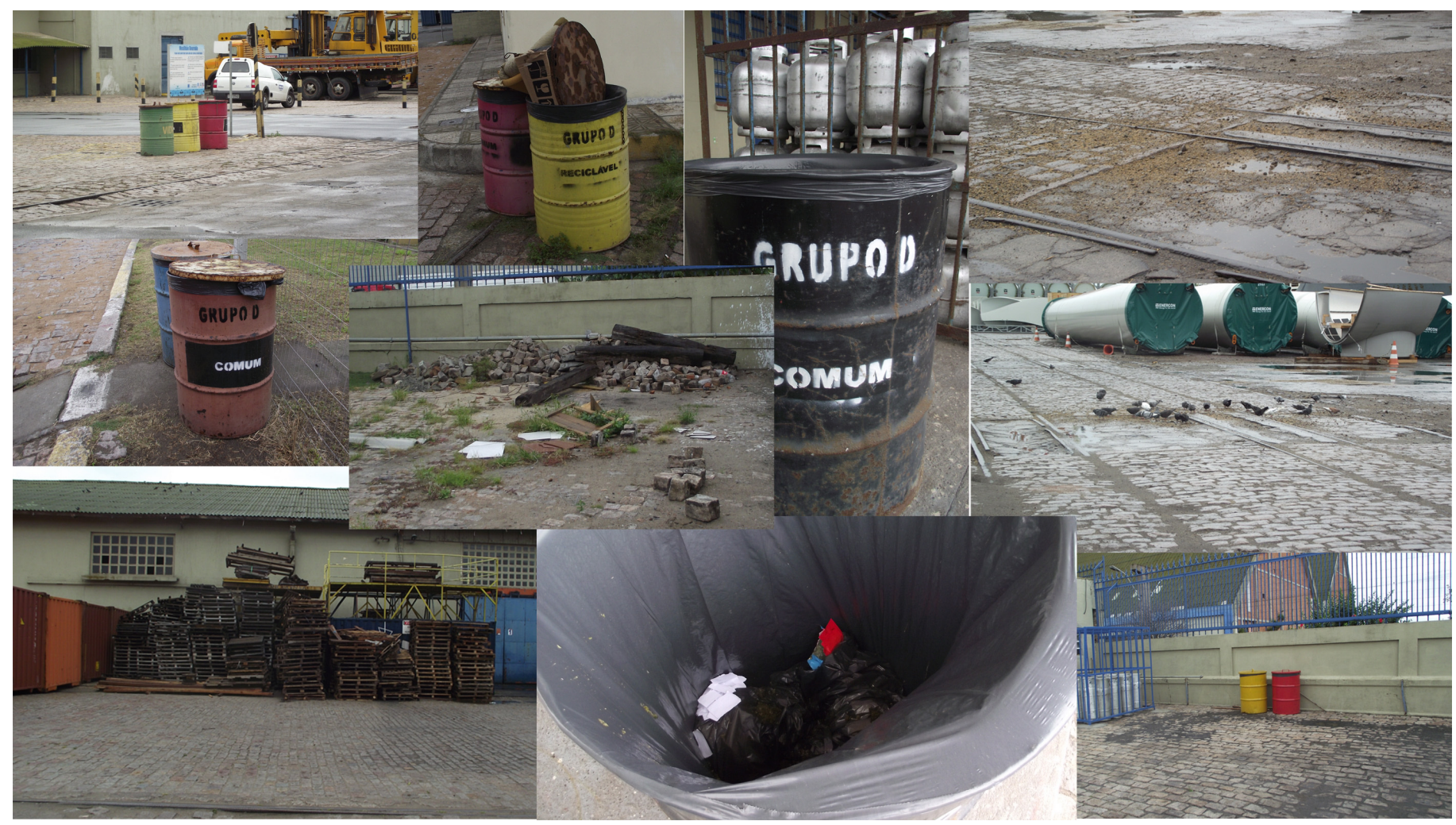

Figura 3. Mosaico da gestão de resíduos no Porto Novo.

Figure 3. Mosaic of waste management in Porto Novo Terminal.

Fonte: O Autor 
A maioria dos operadores vê a Autoridade Portuária como um elemento complicador no processo portuário e náo como uma facilitadora ou um apoio. Essa visão negativa deve ser combatida por meio da discussão franca e aberta, por meio das cobranças coerentes e da demonstraçáo de interesse da Autoridade Portuária. Sem a integração de esforços entre os operadores portuários e a Autoridade Portuária não é possível pensar em gestão, muito menos em gestão ambiental.

\section{CONCLUSÃO}

A gestão de resíduos sólidos se coloca como uma das problemáticas centrais do desenvolvimento sustentável. O correto tratamento dos resíduos, além de beneficiar a população e às organizaçóes (evitando passivos ambientais), pode ser uma fonte de matéria-prima para vários processos produtivos, criando assim um ciclo virtuoso onde, além de tratar corretamente seus resíduos, pessoas e organizaçóes consigam um benefício econômico no processo, seja utilizando materiais reciclados (mais baratos), seja vendendoos, reduzindo vertiginosamente o impacto ambiental causado pelo processo produtivo.

Dada sua complexidade, a regulação da gestão de resíduos sólidos é essencial, e a Política Nacional de Resíduos Sólidos se constitui no cerne legal para que o ciclo virtuoso se sobreponha ao vicioso e para que a gestáo de resíduos sólidos seja um meio que possibilite a redução no consumo, o reaproveitamento de resíduos e sua reciclagem. Dessa forma, promove-se o aumento da vida dos aterros sanitários, a reduçấo dos custos de produção e a geraçáo de renda e inclusão social às pessoas em situaçáo de vulnerabilidade.

Responsáveis pelo escoamento da maior parte das exportaçóes, zonas de pujança econômica e de oportunidades, os portos e as cidades portuárias constituem um marco na história brasileira e um desafio para os gestores, tanto públicos como privados, pois organizar, no sentido de viabilizar o funcionamento eficiente e eficaz, esse mosaico de processos naturais, econômicos, sociais e políticos não é tarefa fácil. O gerenciamento correto dos resíduos gerados nessas estruturas multimodais deve ser uma prioridade para as autoridades portuárias, muitas vezes mais preocupadas com a atração de investimentos e a expansão de suas estruturas que com a saúde dos ecossistemas e das populaçóes vizinhas.

Desde um ponto de vista burocrático e administrativo a gestáo de resíduos sólidos do Terminal Porto Novo do Porto do Rio Grande atende às especificaçóes legais, porém, na prática, não foi constatada uma gestão estruturada dos resíduos, apenas uma tentativa de cumprir com a exigência legal de possuir um documento de gestão bem estruturado, o que caracteriza uma gestáo voltada para o atendimento de imposiçóes legais e pouco preocupada com a prática e com a realidade das operaçóes desenvolvidas em sua área de abrangência.

A gestão de resíduos na área de abrangência do corrente estudo, não se resume a um problema pontual, mas tratase de uma questâo sistêmica e como tal deve ser tratada. Apenas com o esforço conjunto da Autoridade Portuária e dos usuários do porto será possível encontrar uma solução adequada a esses problemas.
Cabe ressaltar que a ação dos empreendedores presentes no porto não foi ainda avaliada, podendo contribuir positiva ou negativamente para a gestáo de resíduos sólidos. Em entrevistas com alguns empreendedores notou-se um individualismo nas açóes propostas e adotadas o que pode caracterizar um processo entrópico na gestão. Cada empresa busca solucionar seus problemas, mesmo dividindo espaços. Essas açóes, ao invés de serem sinérgicas, acabam sendo concomitantes e entrópicas, resultando em uma duplicação de esforços e custos para atender a um mesmo problema.

Iniciativas como o Projeto Transaqua, financiado pelo FINEP, que busca caracterizar a gestão ambiental portuária e o Projeto de Implantação do Programa de Conformidade do Gerenciamento de Resíduos Sólidos e Efluentes Líquidos nos Portos Marítimos Brasileiros, incentivado e financiado pela Secretaria Especial de Portos, com recursos do Plano de Aceleraçáo do Crescimento do Governo Federal, são fundamentais para que as Autoridades Portuárias sejam abastecidas de conhecimentos técnicos válidos e assim consigam efetuar uma gestão ambiental efetiva.

A Divisão de Meio Ambiente Saúde e Segurança (DMASS) mostrou-se extremamente solícita com todas as demandas desta pesquisa e interessada nos produtos oriundos da mesma. Cabe ressaltar que a caracterização do estado da gestão é o primeiro passo para que as realidades encontradas ao longo do trabalho possam ser modificadas e que uma nova visão a respeito da gestão ambiental possa surgir, possibilitando a integração de esforços por parte dos empreendedores e da Autoridade Portuária.

\section{BIBLIOGRAFIA}

ANTAQ (2011) - Porto Verde: Modelo Ambiental Portuário. 107p., ANTAQ - Agência Nacional de Transportes Aquaviários, Brasília, DF, Brasil. ISBN: 9788564964013. Disponível em: http://www.antaq.gov.br/ Portal/pdf/PortoVerde.pdf

Carvalho, L.E.X. (2001) - Desenvolvimento de Solução Integrada de Sistemas de Limpeza Urbana em Ambiente SIG. 340p. Dissertação de Mestrado, Universidade Federal do Rio de Janeiro. Rio de Janeiro, RJ, Brasil. Não publicado.

Cicin-Sain, B.; Knecht, R.W. (1998) - Integrated Coastal and Ocean Management: Concepts and Practices. 517p., Island Press, Washington, DC, U.S.A. ISBN: 1559636033

Comissão Mundial Sobre Meio Ambiente e Desenvolvimento (1991) - Nosso Futuro Comum. 2a edição, 430p., tradução da ediçáo em inglês Our Common Future, publicado pela Oxford University Press (1987), Editora da Fundação Getúlio Vargas, Rio de Janeiro, RJ, Brasil.

Kitzman, D.(2010) - Ambiente Portuário, 158p. Editora FURG, Rio Grande, RG, Brasil. ISBN: 978-85-7566$170-3$

MDIC (2012) -Balança Comercial Brasileira. MDIC - Ministério do Desenvolvimento, Indústria e Comércio, DEPLA - Departamento de Planejamento e Desenvolvimento do Comércio Exterior, Brasília, DF, Brasil. Disponível em http://www.mdic.gov.br/sitio/ interna/interna.php?area $=5 \&$ menu $=1161$. 
Mesquita Jr, J.M. (2007) - Gestão integrada de resíduos sólidos. 40p., IBAM, Rio de Janeiro, RJ, Brasil. Não Publicado.

MMA (2002) -Projeto Orla: Fundamentos para a Gestão Integrada. 74p., MMA - Ministério do Meio Ambiente, SQA - Secretaria de Qualidade Ambiental nos Assentamentos Humanos / MP - Ministério do Planejamento, Orçamento e Gestão, SPU - Secretaria do Patrimônio da Uniāo, Brasília, DF, Brasil. Disponível em: http://www.planejamento.gov.br/secretarias/upload/ Arquivos/spu/publicacao/081021_PUB_ProjOrla_ fundamentos.pdf.

MMA (2011) - Plano Nacional de Residuos Sólidos. Versão Preliminarpara ConsultaPública.102p., MMA-Ministério do Meio Ambiente, Brasília, DF, Brasil. Disponível em http://www.cnrh.gov.br/pnrs/documentos/consulta/ versao_Preliminar_PNRS_WM.pdf

Porto, M.M. (2006) - Portos e o Desenvolvimento. p.208. Lex Editora, São Paulo, SP, Brasil. ISBN: 9887364588.

Presidência da República (2000) - Lei 9.966, de 28 de abril de 2000. Dispóe sobre a prevenção, o controle e a fiscalização da poluiçáo causada por lançamento de óleo e outras substâncias nocivas ou perigosas em águas sob jurisdição nacional e dá outras providências. Publicado no DOU - Diário Oficial da União de 24.4.2000, Brasília, DF, Brasil.. Disponível em http:// http://www.planalto.gov.br/ccivil_03/leis/ L9966.htm
Presidência da República (2010) - Lei 12.305, de 02 de agosto de 2010. Institui a Politica Nacional de Residuos Sólidos; altera a Lei no 9.605, de 12 de fevereiro de 1998; e dá outras providências. Publicado no DOU - Diário Oficial da Uniāo de 3.8.2010, Brasília, DF, Brasil.. Disponível em http://www.planalto.gov.br/ccivil_03/_ato20072010/2010/lei/112305.htm

Seiffert, M.E.B. (2007) - ISO 14.000 Sistemas de Gestão Ambiental: implantação objetiva e econômica. 258p. Editora Atlas, São Paulo, SP, Brasil. ISBN: 978-8522447701.

SUPRG (2010) - Plano de Gerenciamento de Resíduos Sólidos (PGRS). 69p. SUPRG - Superintendência do Porto do Rio Grande. Rio Grande, RS, Brasil. Não Publicado.

SUPRG (2011) - Plano de Zoneamento das Áreas do Porto organizado do Rio Grande. 11p., SUPRG Superintendência do Porto do Rio Grande, Rio Grande, RS, Brasil. Não Publicado.

Valle, C.E. (2006) - Qualidade Ambiental: ISO 14.000. 200p. Senac, São Paulo, SP, Brasil. ISBN: 8573592842

Yin, R.K. (2010) - Estudo de Caso: Planejamento e Métodos. 248p. Bookman, Porto Alegre, RS, Brasil. ISBN: 9788577806553.

Zveibil, V.Z. (coord.) (2001) - Manual de Gerenciamento Integrado de Residuos Sólidos. 193p. IBAM - Instituto Brasileiro de Administração Municipal, Brasília, DF, Brasil. Disponível em http://www.resol.com.br/cartilha4/ manual.pdf. 